\title{
Relationship between Procrastination as One of the Personality Traits and Disaster Preparedness in Tehran, Iran
}

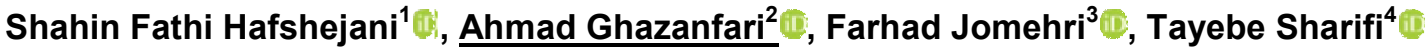

Date of submission: 30 Aug. 2021 Date of acceptance: 3 Oct. 2021

\section{Original Article}

Abstract

INTRODUCTION: Disaster preparedness is one of the most important components of reducing vulnerability, which is poorly considered in Tehran, Iran. Several factors and personality traits are involved in this negligence. This study aimed to investigate the procrastination trait and its relationship with disaster preparedness levels in Tehran, Iran.

METHODS: This descriptive-correlational study was conducted between 2018 and 2021 using structural equation modeling. The statistical population of this study was citizens in Tehran, Iran. A sample size of 419 cases was included in this study. Standard tests have also been utilized to investigate the variables.

FINDINGS: Based on the obtained results, according to the coefficients reported in the model, it can be observed that procrastination has no significant effect on disaster preparedness.

CONCLUSION: Procrastination and experiences gained affect people's preparedness for disaster. According to the results, the preparedness of the people of Tehran for accidents is very low.

Keywords: Disaster Preparedness; Personality Traits; Procrastination.

How to cite this article: Fathi Hafshejani SH, Ghazanfari A, Jomehri F, Sharifi T. Relationship between procrastination as One of the Personality Traits and Disaster Preparedness in Tehran, Iran. Sci J Rescue Relief 2021; 13(4): 312-17.

\section{Introduction}

$\mathrm{I}$ ran is one of the countries that is threatened by many hazards, the most common of which are natural disasters, such as floods and earthquakes, as well as man-made catastrophes, including fires and accidents (1). A total of 1,000 earthquakes occur annually in Iran, of which 240 cases are earthquakes with a magnitude over 4 on the Richter scale. According to the available statistics, a major earthquake and an earthquake with a magnitude of 6 on the Richter scale occur annually and every 10 years, respectively, which indicates the strong seismicity of this region. According to the reports of the International Federation of Red Cross and Red Crescent Societies regarding the global impact of injuries, Iran has ranked fourth in Asia in terms of accident rates after China,
India, and Bangladesh. On the other hand, the population of Iran during the last hundred years has always been about $1 \%$ of the world's population; however, the casualties due to earthquakes and natural disasters account for about $6 \%$ of the world's deaths (1). The history of disasters in Iran confirms that natural hazards, such as floods, earthquakes, and landslides, as well as man-made hazards, such as road accidents and explosions, have made Iran one of the top 10 countries in terms of the rate of natural disasters in the world. A large number of victims of disasters and accidents in Iran have shown that the majority of the people are not prepared for disasters that disrupt or interrupt basic services in the community. A study conducted in 2012 by the Ministry of Health and

1- PhD Candidate, Department of Psychology, Shahrekord Branch, Islamic Azad University, Shahrekord, Iran

2- Associate Professor, Department of Psychology, Shahrekord Branch, Islamic Azad University, Shahrekord, Iran

3- Assistant Professor, Department of Psychology, Shahrekord Branch, Allameh Tabatabai University, Tehran, Iran

4- Assistant Professor, Department of Psychology, Shahrekord Branch, Islamic Azad University, Shahrekord, Iran Corresponding author: Ahmad Ghazanfari, Email: aghazan5@yahoo.com 
Medical Education through the health network system showed the same claim. According to this study, the preparedness of Iranian families has been equal to $8.55 \%$, which has reached $9.3 \%$ in 2015 with the intervention and implementation of the program for the assessment and training of family preparedness for disasters.

A study was conducted in 2014 in Tehran, Iran, (the joint project of the International Federation of Red Cross and Red Crescent Societies in reducing risks in urban areas and selecting Tehran as one of the pilot cities for public education), and part of the results showed that $93.3 \%$ of the respondents considered their level of preparedness as average and below average for the necessary measures before, during, and after the occurrence of disasters. Moreover, the majority of the respondents $(58.5 \%)$ reported their low levels of eagerness to learn the issues related to the necessary measures before, during, and after the occurrence of disasters (2).

What factor or factors make people procrastinate learning the measures to prevent accidents? Why do not people feel obligated to learn these measures? Why they are not prepared for major disasters and accidents? What factors may be involved in changing their attitude toward preparedness? Or lead to a change in their behavior? Can preparedness be different in different developed and developing societies? How effective can cultural differences be? There are thousands of other questions that can be addressed in this regard.

Personality traits can still be studied as one of the main effective parameters in human behavior. In this study, an attempt will be made to consider it as an independent variable in the proposed model. Procrastination is also investigated as one of the personality traits in this model. It is worth mentioning that in some cases, procrastination has been viewed as a personality disorder (3).

Cohn and Ferrari consider procrastination a culturally related factor $(5 \& 6)$. Research on the relationship between procrastination and the five major personality factors has shown a significant association between the two factors of neuroticism and conscientiousness (7). Parish (2014) believes that procrastination is a personality trait. Moreover, he states that according to the studies, there is an overlap between procrastination as a personality trait and five major personality traits.

Other studies have investigated the relationship between procrastination and performance (8).

Accordingly, this question is raised: "Does procrastination affect people's preparedness for disasters?" It is hypothesized that the answer is "Yes".

According to the growing trend of urbanization, it is predicted that by 2050 , the urban to rural ratio in the world will be $70 / 30$ (2); however, Iran has crossed this ratio for many years. Urbanization today has become a phenomenon that is threatened by many dangers. Both natural and man-made events, if occur in cities, can have irreparable effects given the state of urban construction and density of cities, especially since the growing trend of urbanization shows itself more in the suburbs. In these areas, immigrants with little wealth and low financial capacity, choose a shelter for themselves, which mostly do not survive the events. It is also the architectural condition of cities and the high densities in apartments and skyscrapers that will cause a lot of casualties if they have an accident. The fire-induced collapse of the Plasco building in Tehran in December 2016 is an example of a catastrophic accident that is predicted for other buildings in Tehran.

Tehran is of great importance since it is the capital of Iran and encompasses more than onefifth of the total population of the country; moreover, it is the political and economic center of Iran. The city is surrounded by dangerous faults. According to research conducted by a group of Japanese researchers (JICA), if the north and south faults of Tehran are activated together, a catastrophe will occur which will be called the most important accident and catastrophe in history in terms of the victims of the accident and the extent of the destruction.

There are currently more than 10 million people in Tehran, which is largely defenseless against disasters, such as floods, earthquakes, as well as urban disasters. People also do not have the necessary awareness of this important thing, and if they do, they do not really pay attention to it (2). The investigation of the variables of this study may lead us to a model that helps us act based on various variables under study so that crisis management practitioners can utilize it to 
increase public preparedness for disasters and reduce the number of victims of accidents. Today, crisis management practitioners use different methods to make people aware of the dangers around them, including inducing fear, persuasion, and change of attitude. However, research shows that people are still indifferent to the dangers around them, and if a major accident happens - as predicted for Tehran-people are not prepared (Iran Ministry of health and medical education, 2014).

\section{Methods}

This descriptive-correlation study used structural equation modeling. Accordingly, after determining the population, selecting the sample, and randomly allocating the individuals in different groups to perform the tests, the information was collected, and the relationship of variables in a structural equation was analyzed in SPSS and AMOS software. The present study explains a part of this model to investigate the relationship between procrastination and disaster preparedness. The formula for determining the sample size was used to identify the sample size. Since in the present study, there is no reliable estimation of the desired ratio in Tehran or similar cities, this ratio is assumed to be $50 \%$. Moreover, considering the error level of 0.05 and confidence interval of $95 \%$, the sample size was estimated at 384 people. However, for more accuracy due to the sample attrition or the non-cooperation of some cases, the final sample size was determined at 419 individuals.

The 20-item Lay's procrastination questionnaire was used in this study to measure procrastination

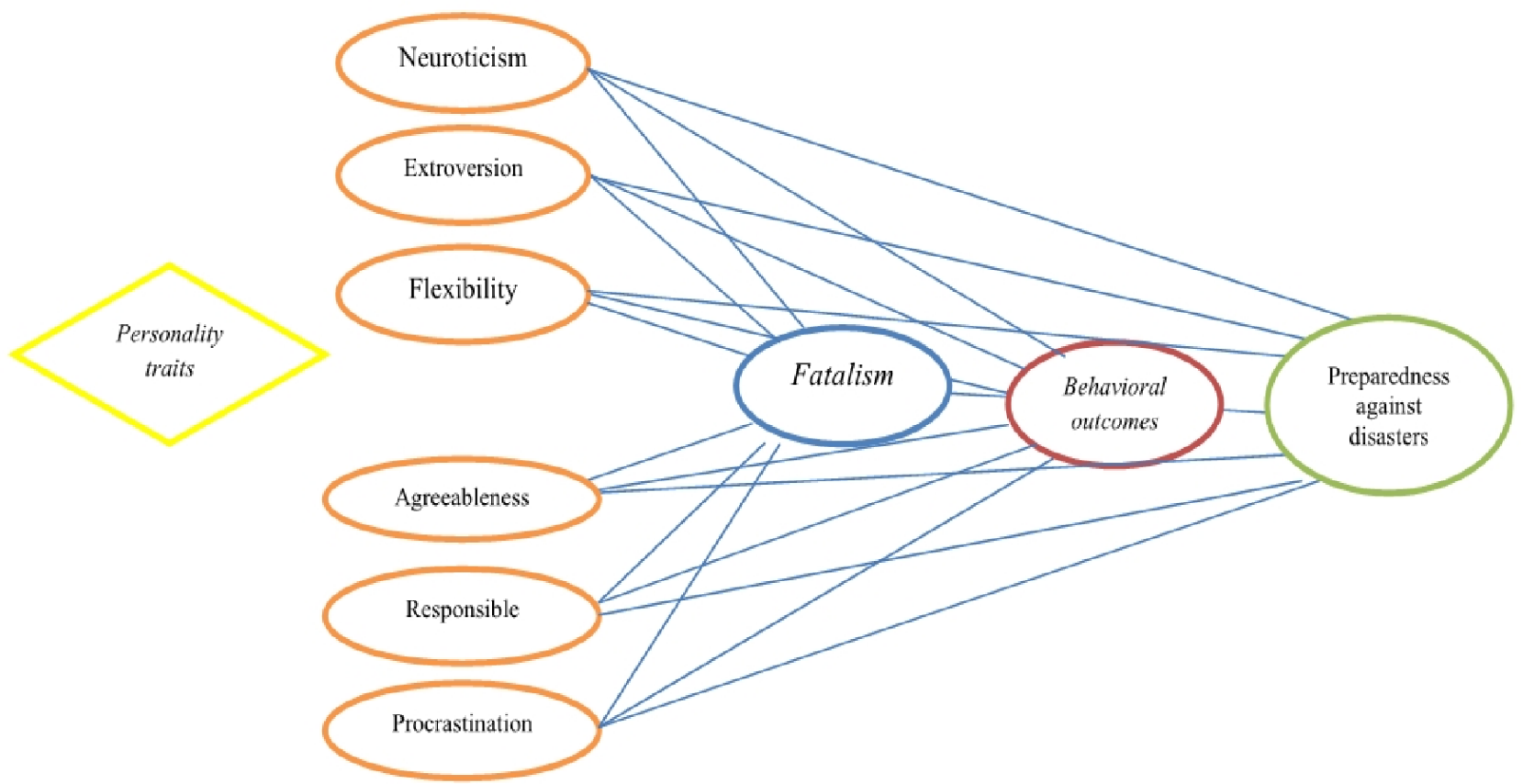

Figure 1. Structural model investigating the effect of personality traits and mediating variables on disaster preparedness (the relationship between procrastination and disaster preparedness)

rated on a five-point Likert scale. This questionnaire has been used in the studies conducted in this field in Iran. This questionnaire has been used in research conducted in this field in the country. Preparation or preparedness is a long-term development plan that aims to strengthen the capacity and efficiency of a country to effectively manage all types of emergencies from the pre-crisis stage to the reconstruction phase and return to the sustainable development phase (9). In this process, each person, as a member of a community, identifies the risks around him and learns the necessary preparatory measures for the time of dealing with accidents. In this community, crisis management is administered based on a prepared community. Preparedness for events and accidents was measured based on the Public Readiness Index in this study.

\section{Findings}


Initially, the participants are described in terms of demographic characteristics. Accordingly, frequency, frequency percentage, and cumulative frequency percentage have been reported for each variable. Table 1 tabulates the frequency distribution of education level in the participants.

As can be observed in Table 1, out of 419 participants in this study, $30.8 \%$ and $11.9 \%$ of the cases had diploma and associate degrees, respectively. Moreover, $35.8 \%$ and $20 \%$ of the participants had bachelor's and master's degrees, respectively. It is worth mentioning that doctoral or higher degrees include $4.3 \%$ of the respondents.

According to Table $2,45.6 \%$ and $54.2 \%$ of the participants are male and female, respectively.

As shown in Table 3, $15.8 \%$ and $24.9 \%$ of the participants were in the age groups of $18-25$ and 26-36 years, respectively. Moreover, $30.1 \%$ and $15.1 \%$ of the cases were in the age groups of $37-$
47 and 48-58 years, respectively. It should be noted that those who were over 58 years included $14.1 \%$ of the respondents.

As can be observed in Table 4, the mean age of the participants was between 26 and 36 years, and the median of the education level was estimated at 4. Furthermore, the results of the Spearman correlation coefficient showed that this variable has a relationship with education level $\quad(0.1)$ and age $(0.18) \quad(\mathrm{P}<0.05)$. Accordingly, higher education levels lead to more preparedness for disasters. In addition, preparedness for events increases with an increase in age $(\mathrm{P}<.05)$.

According to Table 5, the mean \pm SD procrastination is estimated at $33.36 \pm 5.41$. In addition, there is a significant relationship between disaster preparedness and procrastination $(\mathrm{r}=0.17)$. Therefore, a decrease in the procrastination scores leads to an increase in the scores of disaster

Table 1. Frequency distribution of the participants regarding the level of education

\begin{tabular}{c|ccc}
\hline Education level & Frequency & Frequency percentage & Cumulative frequency percentage \\
\hline Diploma degree & 114 & 27.2 & 30.8 \\
Associate degree & 50 & 11.9 & 39.4 \\
Bachelor's degree & 150 & 35.8 & 75.5 \\
Master's degree & 84 & 20 & 95.7 \\
Doctoral degree and higher & 18 & 4.3 & 100 \\
\hline
\end{tabular}

Table 2. Frequency distribution of the participants regarding gender

\begin{tabular}{c|c|c|c|}
\hline Gender & Frequency & Frequency percentage & Cumulative frequency percentage \\
\hline Male & 192 & 45.6 & 45.7 \\
Female & 227 & 54.2 & 100 \\
\hline
\end{tabular}

Table 3. Frequency distribution of the participants regarding age

\begin{tabular}{cccc}
\hline Age & Frequency & Frequency percentage & Cumulative frequency percentage \\
$18-25$ & 66 & 15.8 & 15.8 \\
$26-36$ & 104 & 24.9 & 40.7 \\
$37-47$ & 126 & 30.1 & 70.8 \\
$48-58$ & 63 & 15.1 & 85.9 \\
59 & 59 & 14.1 & 100 \\
\hline
\end{tabular}

Table 4. Descriptive indices and correlation coefficients of demographic variable scores with disaster preparedness

\begin{tabular}{ccccc} 
Components & Mean & Standard deviation & Correlation & Significance level \\
\hline Education level (median) & 4 & - & 0.1 & 0.042 \\
Age & 4.01 & 1.53 & 0.18 & 0.001 \\
\hline
\end{tabular}

Table 5. Descriptive indices and correlation coeff3icient between procrastination and disaster preparedness

\begin{tabular}{cccccc}
\hline Variable & Mean & Standard deviation & Correlation coefficient & Significance level \\
\hline Procrastination & 33.36 & 5.41 & 0.17 & 0.001 \\
\hline
\end{tabular}

preparedness. In other words, less procrastination in the personality traits of the participants results in more preparedness behavior for disasters. This is a simple relationship based on Pearson correlation. 
This was an evaluation of a simple relationship between variables and the criterion variable that was examined before the model investigation. However, it was necessary to investigate this association using a model. Table 6 summarizes the details of the structural equation modeling, the estimations related to the most important parameters in the model (direct effects), and the study of significant or nonsignificant differences related to these effects.

The estimated values in Table 6 indicate that personality traits have no statistically significant and direct effect on disaster preparedness.

Table 6. Review of significant or non-significant indices

\begin{tabular}{|c|c|c|c|c|c|c|c|}
\hline \multirow{2}{*}{$\begin{array}{l}\text { Independent } \\
\text { variable }\end{array}$} & \multirow[b]{2}{*}{ Path } & \multirow[b]{2}{*}{$\begin{array}{c}\text { Dependent } \\
\text { variable } \\
\end{array}$} & \multicolumn{2}{|c|}{ Estimation } & \multirow{2}{*}{$\begin{array}{l}\text { Critical } \\
\text { ratio } \\
\end{array}$} & \multirow{2}{*}{$\begin{array}{c}\begin{array}{c}\text { Significance } \\
\text { level }\end{array} \\
\end{array}$} & \multirow{2}{*}{$\begin{array}{l}\text { Determination } \\
\text { coefficient }\end{array}$} \\
\hline & & & $\begin{array}{c}\text { Non- } \\
\text { standard }\end{array}$ & Standard & & & \\
\hline \multirow{4}{*}{$\begin{array}{l}\text { Personality traits } \\
\text { Neuroticism } \\
\text { Procrastination } \\
\text { Behavioral } \\
\text { consequences }\end{array}$} & & \multirow{4}{*}{$\begin{array}{l}\text { Preparedn } \\
\text { ess for } \\
\text { accidents } \\
\text { and events }\end{array}$} & 0.173 & 1.9 & 1.653 & 0.09 & \multirow{4}{*}{0.4} \\
\hline & & & 0.032 & 0.491 & 1.463 & 0.14 & \\
\hline & & & -0.087 & -0.551 & -0.805 & 0.42 & \\
\hline & $\longrightarrow$ & & -0.202 & -0.14 & -0.513 & 0.6 & \\
\hline
\end{tabular}

\section{Discussion and Conclusion}

As mentioned before, this study was extracted from a research project to investigate the effects of personality traits along with several mediating variables on the preparedness of citizens in Tehran for accidents and events using a structural model. Out of all variables presented in the research, this study evaluated two variables (the relationship between procrastination as a personality trait and disaster preparedness as a dependent variable). Procrastination is a habit that exists in many people, and researchers believe that it is a feature of human nature (10). The Latin verb procrastinare means to put off until morning. This word is equivalent to delaying, postponing, or neglecting (11). Therefore, the word itself evolved from the prefix pro-, meaning "forward," and crastinus, meaning "of tomorrow". Procrastination seems to make a person's life more enjoyable; however, it soon brings stress, confusion, and failure (12). Some researchers have identified procrastination as a behavioral problem. Accordingly, procrastination is recognized as a behavioral problem, and the goal of treatment is to reduce the proportion or percentage of procrastination time and increase the proportion or percentage of study or activity. Others believe that procrastination is a cognitive problem. In this view, procrastination is based on wrong/irrational thoughts and beliefs about the conditions and results of the activity.

On the other hand, some believe that procrastination is a motivational problem. In this view, procrastination is not due to laziness or lack of motivation but a fact that procrastinators are interested in doing something else. Procrastination can be a habit that ultimately lowers one's expectations of self-efficacy. It is also regarded as a personality disorder. In this view, procrastination is known as a weakness and conflict with characteristics, such as reluctance, lack of perseverance, laziness, lack of attention, and weakness of power-seeking (3). With this background in mind and considering the view of procrastination and the fact that Iranians do things at the eleventh hour, the question raised is "What effects does this feature have on the level of people's preparedness for disasters?". Probably, one of the variables that could justify this level of unpreparedness was this personality trait, which the authors thought was the case; accordingly, one of the assumptions was the relationship between procrastination and people's preparedness for disasters. In other words, higher levels of procrastination lead to fewer levels of preparedness. As mentioned in the analysis of the results, a simple investigation through Pearson correlation confirmed the research hypothesis; however, the results of structural equation modeling showed no statistically significant association in this regard, and procrastination could not predict disaster preparedness. According to the results, the research hypothesis about the effect of procrastination on disaster preparedness was not confirmed.

In the present study, due to the prevalence of coronavirus and lack of proper access to the participants to complete the questionnaires in person, unwanted bias may have been present in the results; therefore, generalizability should be made with caution. It is suggested that this study be conducted using a larger sample size and identifying more subgroups after the end of the 
coronavirus epidemic.

\section{Acknowledgments}

The authors would like to thank all the participants and those who contributed to conducting this study.

\section{Conflict of Interests}

None

\section{Authors' Contribution}

This study was extracted from a Ph.D. dissertation in Psychology. Shahin Fathi executed the study and wrote the manuscript; Ahmad Ghazanfari, Farhad Jomehri, and Tayebe Sharifi wrote the methodology and result sections.

\section{References}

1. Abdollahi M. Crisis Management in Urban areas. Tehran: Municipalities Organization and villages publishing. Fifth edition. 2015 (In Persian)

2. Fathi Sh et al. Participation for management. Reducing urban risk through the impact of public education, Tehran Pilot Project, International Federation of Red Cross and Red Crescent Societies 2017 (In Persian).

3. Golestani Bakht T, Shokri M. The relationship between procrastination and metacognitive beliefs. Bi-Quarterly Journal of Social Cognition. 2013; Vol 2, No.2 (In Persian)

4. Díaz-Morales, JF, Ferrari, JR, Cohen, JR. Indecision and avoidant procrastination: The role of morningness-eveningness and time perspective in chronic delay lifestyles. The Journal of General Psychology 2008; 135: 228-240.

5. Yan J. Yang J. Trait procrastination and compulsive Internet use as predictors of cyber loafing, in 11th International Conference on Service Systems and Service Management (ICSSSM), 2014, pp.1-4, doi: 10.1109/ICSSSM.2014.6874119

6. Zhou J, Urhachne D. Self-regulated Learning the museum: understanding the relationship of visitor's goals, learning strategies and appraisals. Scandinavian Journal of Educational Research, 2017; No.61

7. Larson MA. Procrastination and performance, does experience moderate the effects? [Dissertation].Angelo State University; 2008.

8. Alamdari, Shahram. Ready Society, Aria
Kohan Noandishan Publications 2004 (In Persian).

9. Sirois, F.M. Procrastination and stress: Exploring the role of self-compassion self and Identity, 2014; 13(2), 128-145

10.Ellis, A. \& Knaus, W. Overcoming procrastination. New York: New American Library. 2002

11.Steel, P. The Nature of Procrastination: A Meta-Analytic and Theoretical Review of Quintessential Self-Regulatory Failure. Psychological Bulletin, 2007;133,65-94 http://dx.doi.org/10.1037/0033-2909.133.1.65 